
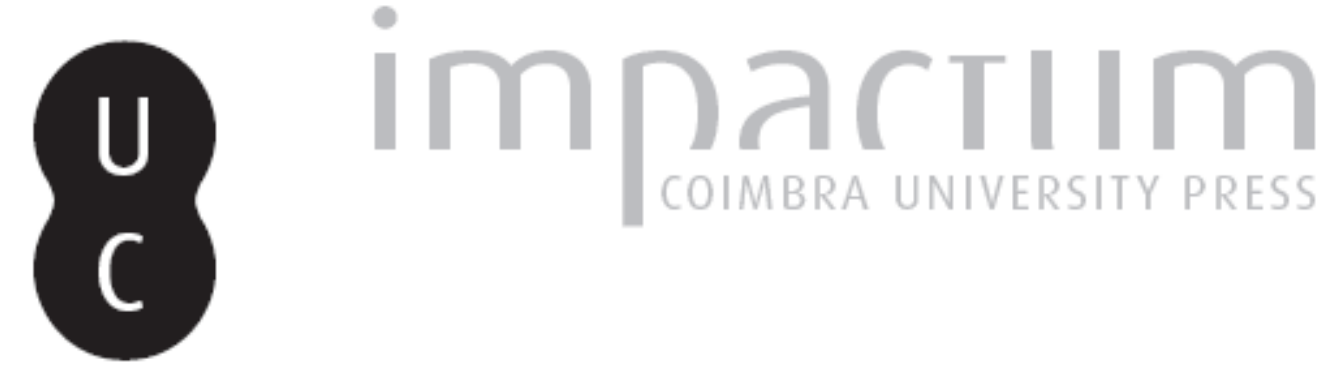

\title{
Geopolítica, economia, (des)colonização e cultura a partir do Ministério das Colónias de Marcelo Caetano 1944-47
}

Autor(es): Barbosa, Márcio

Publicado por: Imprensa da Universidade de Coimbra

URL

persistente:

URI:http://hdl.handle.net/10316.2/40216

DOI:

DOI:https://doi.org/10.14195/2183-8925_34_8

Accessed : $\quad$ 26-Apr-2023 13:17:14

A navegação consulta e descarregamento dos títulos inseridos nas Bibliotecas Digitais UC Digitalis, UC Pombalina e UC Impactum, pressupõem a aceitação plena e sem reservas dos Termos e Condições de Uso destas Bibliotecas Digitais, disponíveis em https://digitalis.uc.pt/pt-pt/termos.

Conforme exposto nos referidos Termos e Condições de Uso, o descarregamento de títulos de acesso restrito requer uma licença válida de autorização devendo o utilizador aceder ao(s) documento(s) a partir de um endereço de IP da instituição detentora da supramencionada licença.

Ao utilizador é apenas permitido o descarregamento para uso pessoal, pelo que o emprego do(s) título(s) descarregado(s) para outro fim, designadamente comercial, carece de autorização do respetivo autor ou editor da obra.

Na medida em que todas as obras da UC Digitalis se encontram protegidas pelo Código do Direito de Autor e Direitos Conexos e demais legislação aplicável, toda a cópia, parcial ou total, deste documento, nos casos em que é legalmente admitida, deverá conter ou fazer-se acompanhar por este aviso.

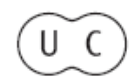



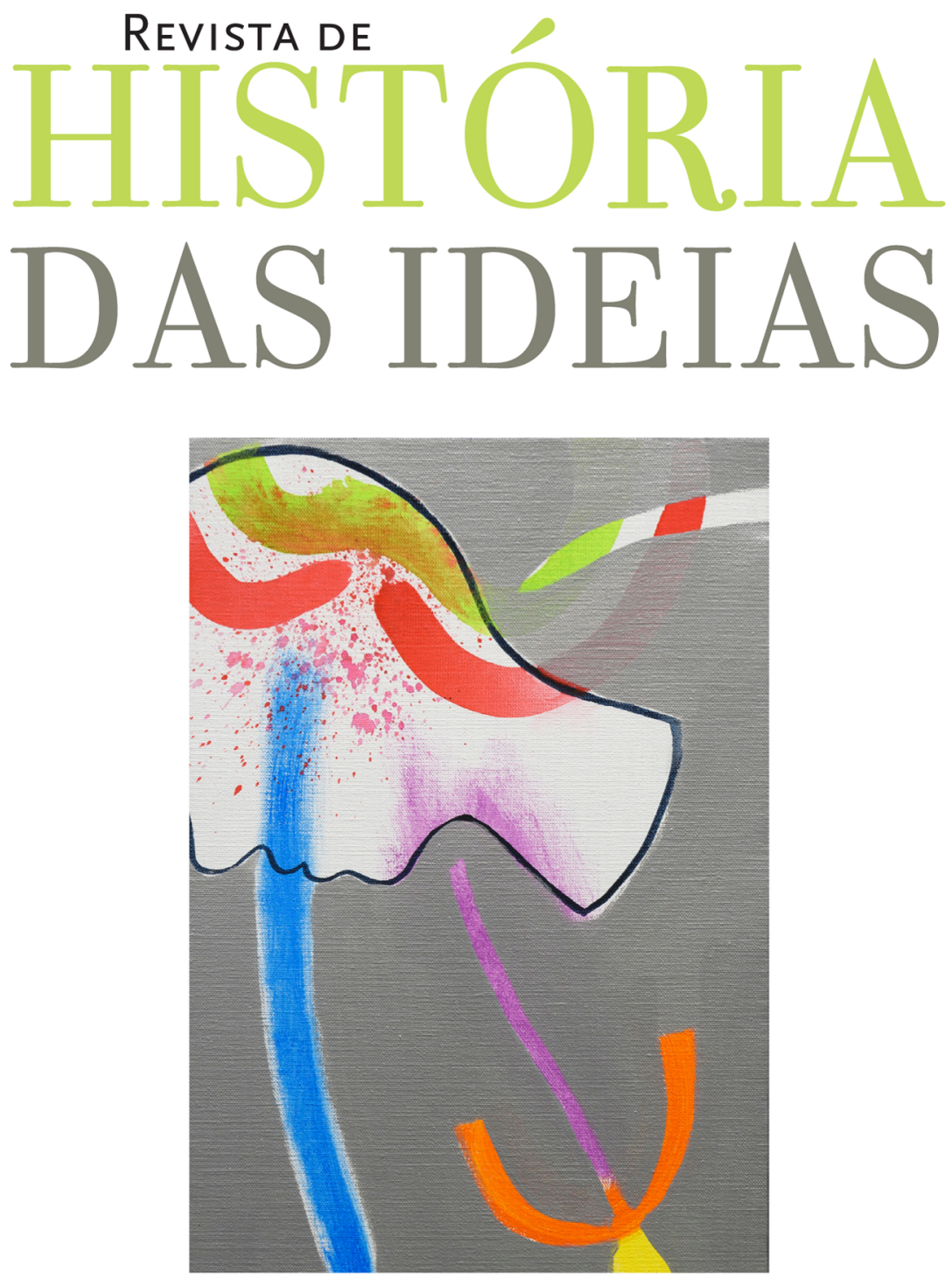

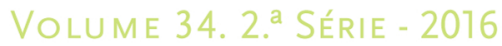




\title{
GEOPOLÍTICA, ECONOMIA, (DES)COLONIZAÇÃO E CULTURA A PARTIR DO MINISTÉRIO DAS COLÓNIAS DE MARCELO CAETANO
} 1944-47

\author{
GEOPOLITICS, ECONOMY, CLLTLIRE AND DECOLONIZATION \\ FROM THE MINISTRY OF COLONIES OF MARCELO CAETANO \\ 1944-47
}

\author{
MÁrcio BARBosa \\ mscb09@hotmail.com \\ CEIS20/UC
}

Texto recebido em / Text submitted on: 20/06/2016

Texto aprovado em / Text approved on: 19/09/2016

\section{Resumo:}

Procura-se aqui construir um quadro, ensaístico e necessariamente breve, da mundividência no Ministério das Colónias liderado por Marcelo Caetano nos anos críticos de 1944 a 1947. Convocam-se sobretudo elementos de complexidade para uma compreensão do posicionamento dos principais atores internacionais ocidentais a partir do pós-guerra, segundo um ângulo de visão pouco estudado. Isto permite ensaiar um exercício de exploração de espaços cinzentos, ambiguidades, contradições ou paradoxos de uma inegável atualidade. Nomeadamente no que diz respeito aos particularismos que caracterizam the english way e american way of life. Em que medida estes particularismos contribuíram para dificultar, mais do que facilitar, processos fundamentais do pós-guerra como a descolonização e o desenvolvimento? De igual modo, em que medida o confronto bipolar (ideológico, propagandístico, etc.) funcionou como acelerador mas também dificultador desses processos? 
Este exercício possibilita também perceber melhor a visão de Marcelo Caetano, que viria a ser o último líder do Estado Novo, sobre a ordem mundial em gestação, os seus problemas e paradoxos, bem como a sua perspetiva sobre a cultura e essa «forma portuguesa de estar no mundo» ou um presumível portuguese way of life.

\section{Palavras-chave:}

Marcelo Caetano, geopolítica, descolonização, cultura, pós-guerra.

\section{Abstract:}

Search here to build a picture, essayistic and necessarily brief, of the world view in the Ministry of the Colonies led by Marcelo Caetano in the critic years 1944 to 1947. We call for particular elements of complexity to an understanding of positioning of the main international actors (in the West) from the post-war period, according to a viewing angle little studied. This allows us to rehearse an exercise in exploitation of grey spaces, ambiguities, contradictions or paradoxes that remained to the present day. In particular, as regards the particularities that characterize the English way and American way of life. To what extent these particularities contributed to impede, rather than facilitate, fundamental processes like post-war decolonization and development? Similarly, to what extent the bipolar confrontation (ideological, propaganda, etc.) worked as an accelerant but also as a destructive element in these processes?

This exercise allows also better understand the vision of Marcelo Caetano, who will be the last leader of the Estado Novo (1968-74), on the world order in gestation, its problems and paradoxes, as well as his perspective on the culture and the Portuguese way of being in the world or a alleged «Portuguese way of life».

\section{Keywords:}

Marcelo Caetano, geopolitics, decolonization, culture, post-war period.

\section{A complexificação do(s) Poder(es ) no período entre guerras}

Poder governar não é necessariamente Poder. Como defendeu Michel Foucault (1926-1984), o poder é uma relação, não uma posse ${ }^{(1)}$. Segundo Marcelo Caetano (MC - 1906-1980), «a política é um meio ingrato de ação»(2). A lei da complexidade crescente das realidades nacionais e

(1) Michel Foucault, Vigiar e punir: nascimento da prisão, 10ª ed., Petrópolis, Vozes, 1993 (original de 1975).

(2) AMC, cx. 26, Correspondência/ Ferreira, Francisco Gonçalves (secretário de Estado da Saúde e Assistência): n 3 (21/01/72). Resposta de MC ao pedido de demissão do autor (aceite e decretado em 31/01/72). 
internacional contemporânea, com a introdução contínua de novas camadas, aí está para o confirmar $^{(3)}$. A glândula pineal de todas as questões será sempre: onde reside(m) efetivamente o(s) Poder(es)?

A universalização do condicionamento da forma de «fazer política» iniciada durante a Grande Guerra, ou seja, a guerra total, que levaria Ernst Junger (1895-1998) a considerar este evento historicamente mais relevante do que a Revolução Francesa ${ }^{(4)}$, não possibilitou a vitória do desvio da noção de «totalidade» protagonizada mais tarde pelo aparelho nazi, empenhado numa teoria gestionária de «estado moderno» ${ }^{(5)}$, mas tornou irreversível a valorização estratégico-política dos meios de mobilização e controlo das «consciências» como eixo da nova «arte de governar». Não por acaso, um dos conselheiros do presidente Wilson em Versalhes foi precisamente Walter Lippmann (1889-1974), o autor de Opinião Pública (1922)(6), que influenciaria profundamente a obra homónima de MC em $1965^{(7)}$.

No rescaldo da guerra, o professor de ciência política Parker Thomas Moon (1892-1936) definia o inalienável valor da propaganda, quer como meio educativo das massas no domínio das relações internacionais, ignorando já os conceitos de estado-nação e de nacionalismo, quer como instrumento para o idealismo democrático e os seus contrários, os totalitarismos nazi-fascista e estalinista ${ }^{(8)}$. Talvez por isso, o pioneiro da então emergente indústria de "public relations» tenha sido Edward Bernays (1891-1995), sobrinho de Freud e responsável pela propaganda e censura nos EUA durante a Grande Guerra ${ }^{(9)}$.

A emergência da poderosa arma da propaganda, das técnicas de persuasão e gestão da democracia de massa (a «grande sociedade»),

(3) Ver, entre outros, Bertrand Russel, O Poder: uma nova análise social, $2^{\mathrm{a}}$ ed., Lisboa, Editorial Fragmentos, 1990. (original de 1938)

(4) Ernst Junger, Lo stato mondiale: organismo e organizzazione, Parma, Ugo Guanda Editore, 1998.

(5) Ver, entre outros, Carl Schmidt, La notion de politique, Paris, Flammarion, 1990.

(6) Walter Lippman, Public opinion, New York, Dover Pub., 2004. Ver também, do mesmo autor, Crépuscule des démocraties?, Paris, Fasquelle, 1956.

(7) Marcelo Caetano, A Opinião Pública no Estado Moderno, Lisboa, 1965.

(8) Parker Thomas Moon, Syllabus on international relations, New York, MacMillan Co., 1925, p. 122.

(9) A propósito de Freud e o «sentido da história», ver Ludwig Marcuse, Freud e a Psicanálise, Lisboa, Livros do Brasil, 2006. Ver particularmente cap. 4, p. 127-147: «Freud, Einstein e Marx». Frase de Freud em epígrafe: «Quando se está convencido das deficiências dos atuais estatutos sociais não se justifica que ainda se coloque ao seu serviço uma educação orientada psicanaliticamente». 
controladas numa primeira fase pelo estado (II Guerra Mundial) e mais tarde também (ou sobretudo?) por poderosas companhias e organizações multinacionais (mais ou menos transparentes), levariam o politólogo Harold D. Lasswell (1902-1978) a considerar que os limites da «competência» dos cidadãos para participarem, por sua iniciativa, na construção da vontade geral, tinham sido irreversivelmente ultrapassados pela complexidade da sociedade ${ }^{(10)}$. Nesse sentido, enquanto Stefan Zweig (1881-1942) se confessava um «sobrevivente incorrigível duma época mais livre e cidadão duma sonhada república mundial» e lamentava a «cavalgada da morte pela mentira organizada, pela propaganda»(11), MC afirmava ter saudades do «doce viver» do século XIX. A realidade de 1938-1940, ainda segundo Zweig, «calou» uma «esgotada»e «exausta» "consciência moral» no mundo. Faria, portanto, todo o sentido a afirmação de Denis de Rougemont (19061985), em 1939:

Entrámos na era das libidos errantes, em busca dum teatro novo. E o primeiro que se lhe deparou foi o teatro político. A política de massas, tal como foi praticada a partir de 1917, não é senão a continuação da guerra total por outros meios (para utilizar uma vez mais, invertendo-a, a célebre fórmula de Clausewitz) $)^{(12)}$.

A crise dos sistemas socio-político-económicos de finais do século XIX e princípios do século $X X$, de matriz eurocêntrica, permitiu o advento do «admirável mundo novo» satirizado em 1932 por Aldous Huxley (1894-1963) ${ }^{(13)}$, recuperando o sublime Cândido de Voltaire - «tudo corre o melhor possível no melhor dos mundos» ${ }^{(14)}$-, por Georges Orwell (1903-1950) em 1949(15) e, antes ainda daqueles, por Yevgeny I. Zamyatin (1884-1937) em 1924 ${ }^{(16)}$.

(10) Harold Lassell, Propaganda Technique in the World War, New York, Alfred Knopf, 1927.

(11) Stefan Zweig, O mundo de ontem: recordações de um europeu, Lisboa, Assírio e Alvim, 2005.

(12) Denis de Rougemont, O amor e o ocidente, Lisboa, Veja, 1999, p. 253.

(13) Aldous Huxley, Admirável mundo novo, Lisboa, Antígona, 2013.

(14) Voltaire, Cândido ou o otimismo, Lisboa, Tinta-da-China, trad., notas e posfácio de Rui Tavares e ilustr. de Vera Tavares, 2006.

(15) George Orwell, 1984, Lisboa, Antígona, 2012.

(16) Yevgeny I. Zamyatin, Nós, Lisboa, Antígona, 2004. 


\section{Magníficas idiossincrasias anglo-americanas?}

Pouco mais de um mês após a Conferência de Casablanca (entre Roosevelt e Churchill), um mês após as derrotas da wehrmacht em Estalinegrado e da kriegsmarine no Mar de Barents, e quando já se adivinhava a derrota do afrika korps no norte de África (verificada em maio/junho), MC escreveu o seguinte ao presidente do Conselho (1 de março de 1943):

Se me fosse dado emitir um voto, falando com aquela franqueza que me é imposta como um dever por 14 anos de colaboração com V. ${ }^{a}$ Ex. ${ }^{a}$ e algum trabalho e sacrifício dado ao Estado Novo desinteressadamente, eu preconizaria uma renovação do pessoal governante. Ainda há pouco Churchill referiu a influência que num momento de crise a mudança de comandos no Norte de África teve na transformação do moral das tropas ${ }^{(17)}$. $V^{a}$ Ex. $^{a}$ não gosta deste processo: noutras ocasiões poderá ter tido razão, agora não tem. A estabilidade governativa deve referir-se ao pessoal que desempenha ou é chamado aos cargos de Governo - não à colação das pessoas a certos postos onde às tantas adormeçam, sem fé, sem vontade, sem forças, subjugadas pelas tarefas que lhes passam por cima. Digo isto tanto mais à vontade quanto é certo que, como V. ${ }^{a}$ Ex. ${ }^{a}$ sabe, não sou candidato. Repito que é preciso agir energicamente e quanto antes. Por toda a parte só se ouve dizer: «Isto está na última, é o fim». Será, Sr. Presidente? Eu por mim custa-me a capitular sem luta: mas não vejo outra coisa à minha volta senão a preparação moral da derrota. E ainda acabaremos por, no final da guerra, ter uma situação internacional magnífica e perdê-la por uma catastrófica situação interna ${ }^{(18)}$.

Claro que MC foi um dos candidatos ${ }^{(19)}$. A remodelação, talvez a mais profunda em 36 anos, aconteceria em setembro de 1944 - «a revolução de

(17) Substituição do general Claude Auchinleck pelo general Harold Alexander e substituição do tenente-general William Gott, morto num ataque inimigo, pelo tenentegeneral Bernard Montgomery.

(18) José Freire Antunes, Salazar Caetano: cartas secretas - 1932-1968, Lisboa, Círculo de Leitores, 1993, p. 113-114.

(19) As anteriores escolhas do presidente do conselho para a pasta das Colónias já haviam suscitado duras críticas junto de MC: AMC, cx. 41, Correspondência/Oliveira, Joaquim Nunes de (procurador à CC; diretor da Faculdade de Farmácia da UP): $n^{\circ} 1$ (23/01/41). 
Setembro»-, quando MC assumiu a pasta das Colónias ${ }^{(20)}$. A previsível derrota alemã seria o principal contributo para essa «magnífica» situação internacional. Significava que a maior potência colonial e velha aliada sairia vencedora. Um mês antes de MC entrar para o governo já havia sido assinado o Acordo Luso-Britânico, que interrompia irreversivelmente a neutralidade portuguesa na II Guerra Mundial ${ }^{(21)}$. No Conselho de Ministros (CM) de 9 de fevereiro de 1945, o presidente do Conselho estabelecia a associação, no âmbito da «alta política», entre a "política imperial», «política constitucional» e a «política externa - a aliança inglesa - a neutralidade». Sintetizada em duas frases: «as razões da nossa esperança. O interesse britânico da preservação da ordem no Ocidente». As únicas preocupações eram a «aragem da democracia» e a "perspetiva da $3^{\text {a }}$ Guerra» - «Nós pudemos não entrar nesta guerra, mas é muito duvidoso que possamos não entrar na próxima» ${ }^{(22)}$.

Mantendo-se a lei queirosiana, o Estado Novo como a «República», com os «territórios maninhos em África», cuja localização os meninos agora decoravam nos bancos de escola, eram (também) uma questão de «política externa». Em novembro de 1944 um elemento do regime partilhava com MC: «Não deixei de ponderar a nossa situação com os olhos postos na cobiça já tradicional de que temos sido alvo por parte de algumas nações coloniais e de que, por certo, voltaremos a sê-lo no após guerra» ${ }^{(23)}$. Sem que lhe pudesse escapar, MC criticava publicamente esse queirosianismo:

(20) A par de MC, as seguintes figuras assumiram então o respetivo cargo no governo: Júlio Botelho Moniz o M. do Interior; Manuel Cavaleiro Ferreira o M. da Justiça; Fernando Santos Costa o M. da Guerra; Américo D. R. Thomaz o M. da Marinha; Augusto Cancela de Abreu o M. das Obras Públicas e Comunicações; José Caeiro da Mata o M. da Educação Nacional; Clotário Luís Supico Pinto o M. da Economia; António Castro Fernandes a Subsecretaria de Estado das Corporações e Previdência; Joaquim Trigo de Negreiros a Subs. de E. da Assistência Social; Joaquim Diniz da Fonseca a Subs. de E. das Finanças; Manuel Gomes de Araújo a Subs. de E. da Guerra; José F. do C. Ribeiro Ulrich a Subs. de E. das Obras Públicas; Roberto de Espregueira Mendes a Subs. de E. das Comunicações; Herculano de Amorim Ferreira a Subs. de E. da Educação Nacional; Albano do C. Rodrigues Sarmento a Subs. de E. do Comércio e Industria; e Albano da C. Pimentel Homem de Melo a Subs. de E. da Agricultura.

(21) Ver, entre outros, Pedro Aires Oliveira, Os despojos da Aliança: a Grã-Bretanha e a questão colonial portuguesa: 1945-1975, Lisboa, Tinta-da-China, 2007.

(22) José Freire Antunes, Salazar Caetano: cartas secretas..., cit., p. 147-148.

(23) AMC, cx. 39, Correspondência/Moura, Álvaro de Mendonça Machado de Araújo Gomes de (deputado): n¹ (28/11/44). 
Tenho ouvido algumas vezes certos historiadores de vista curta explicar sistematicamente os factos da vida portuguesa através dos séculos pelo «condicionalismo externo», - como se em Portugal não houvesse inteligência, vontade, personalidade, e nos limitássemos a ser joguete inconsciente de causas exteriores!(24).

Muito antes de se saber o desfecho da guerra, Churchill e Roosevelt acertaram, em agosto de 1941, os princípios da chamada Carta do Atlântico. O primeiro pretenderia antecipar a entrada do aliado na guerra e o segundo precaver a inevitável participação no conflito. Semelhante raciocínio não deve ser marginalizado na interpretação do artigo $3^{\circ}$ da carta: «Respeitam o direito que assiste a todos os povos de escolherem a forma de governo sob a qual querem viver; e desejam que se restituam os direitos soberanos e a independência aos povos que deles foram despojados pela força». Segundo o Departamento de Estado norteamericano, «the Atlantic Charter of August 1941 was not a binding treaty» ${ }^{(25)}$. Churchill estaria a pensar exclusivamente na Europa e na Ásia ocupadas pelas potências do eixo (motivo pelo qual se distribuíram largos milhares de cópias do documento pelos territórios ocupados) e Roosevelt, na senda dos seus antecessores, teria em mente eliminar as vantagens coloniais europeias ${ }^{(26)}$.

Oexcesso de voluntarismo em transformar aquele documento - a Carta do Atlântico - num antecedente dos vetores que dominaram a política mundial no pós-guerra, nomeadamente o processo descolonizador, assemelha-se sobremaneira à inclusão de Kant entre os vários pioneiros projetistas políticos das organizações e espaços supranacionais que ganharam forma durante o século XX. Ideia que, de todo, aqui não se partilha ${ }^{(27)}$. A capacidade efetiva de sustentar um projeto era mais

(24) Marcelo Caetano, Hoje, como ontem: o Estado Novo, conferência promovida pela UN do Porto no XX aniversário de 28 de Maio, 1946, p. 35.

(25) https:/ / history.state.gov/milestones/1937-1945/atlantic-conf.

(26) Ver Peter Clarke, The last thousand days of the British Empire: Churchill, Roosevelt and the birth of the Pax Americana, New York, Bloomsbury Press, 2008.

(27) No Segundo Artigo definitivo para a Paz Perpétua o filósofo alemão definiu claramente que «o direito das gentes deve fundar-se numa federação de estados livres». Ou seja, o direito das gentes deveria contemplar e concordar com a possibilidade federativa. Mas, com a prudência que o caracterizava, antecipou-se àqueles que até hoje vêm em Kant um pioneiro arquiteto dos emergentes espaços supranacionais/supraestatais com a seguinte advertência: «isto seria uma federação de povos que, no entanto, não deveria ser um Estado de povos», uma vez que estes «formam Estados diferentes, que não devem 
importante do que qualquer artigo da Carta do Atlântico. Em março de 1942 os japoneses quebraram a aura de invencibilidade associada às forças britânicas (e, por conseguinte, europeias) na Ásia. O impacto desse acontecimento foi decisivo para o desenrolar do processo descolonizador, segundo é reconhecido até hoje em Inglaterra pelos mais influentes estrategas político-militares ${ }^{(28)}$. Nesse mesmo ano, Nehru foi preso devido ao Movimento Índia Livre, quando já liderava o Partido do Congresso Nacional Indiano desde 1929. Até aí, a potência colonial britânica nunca teve complexos no exercício da sua soberania, como o testemunha o famoso e violentíssimo massacre de Amritsar, em 1919 ${ }^{(29)}$. Acontecimento determinante para a evolução do movimento independentista indiano. Ao qual Londres procurou mais tarde responder, formalmente, com o descentralizador Ato do Governo da Índia de 1935.

Em junho de 1945, na conferência de S. Francisco, onde foi assinada a Carta da ONU, Churchill era o principal arauto do novo tempo de paz, da boa vontade e do objetivo de "poupar as gerações futuras ao flagelo da guerra». Apenas nove meses depois, a 5 de março de 1946, o mesmo político decidiu antecipar-se em dois anos (contribuindo também dessa forma para o que viria a acontecer?) à proclamação das democracias populares na Europa de leste e cunhou a famosa cortina de ferro. Exortou então, algo equivocamente, o mundo ocidental (Europa

fundir-se num só». Antes sugeria uma Federação da Paz, que «não se propõe obter o poder do Estado, mas simplesmente manter e garantir a paz de um Estado para si mesmo e, ao mesmo tempo, a dos outros Estados federados, sem que estes devam por isso (como os homens no estado de natureza) submeter-se a leis públicas e à sua coação». Fiel ao seu pensamento matemático, transcendentalmente infinito, afirmou que a persecução de tal federação deve conter o pressuposto da sua extensão a todo o mundo, caso contrário «a torrente da propensão para a injustiça e a inimizade só poderá ser detida, não pela ideia positiva de uma república mundial (se é que tudo não se deve perder), mas pelo sucedâneo negativo de uma federação antagónica à guerra, permanente e em contínua expansão, embora com o perigo constante da sua irrupção». No Terceiro Artigo definitivo para a Paz Perpétua - «o direito cosmopolita deve limitar-se às condições da hospitalidade universal» Kant admitiu não existir nenhum direito de hóspedes, mas sim «um direito de visita, que assiste todos os homens para se apresentar à sociedade, em virtude do direito da propriedade comum da superfície da Terra». Immanuel Kant, A Paz Perpétua e outros opúsculos, Textos Filosóficos, Lisboa, Edições 70, 1995.

(28) Ver Rupert Smith, A utilidade da força: a arte da guerra no mundo moderno, Lisboa, Edições 70, 2008, p. 246.

(29) Ver, entre outros, Nigel Collet, The butcher of Amritsar: general Reginald Dyer, London, Continuum, 2006; Barbara D. Metcalf, Thomas R. Metcalf, A concise history of modern India, Third Edit., Cambridge University Press, 2012. 
ocidental e América do Norte) a «esmagar o comunismo mundial» em nome da «democracia anglo-saxónica» ${ }^{(30)}$.

Como resulta evidente, a definição de Conceitos Estratégicos Nacionais (CEN) ficou exponencialmente dificultada nesse período. Possivelmente inspirado em Kant ${ }^{(31)}$, MC diria, em 1951, o seguinte a esse respeito:

Se a situação doméstica é inquietante, que diremos da que o Mundo apresenta? A guerra de 1939 não terminou de direito, porque ainda não está assinado o principal tratado de paz, e bem se pode afirmar que também não cessou de facto. Estamos num regime de precário armistício entre duas conceções do homem e a vida moral que se entrechocaram, mas numa confusão lastimável na qual havia de tudo em ambos os campos. As tentativas de construção do novo Direito Internacional têm, por esse motivo, sido imensamente frágeis. Para mais falta-lhes de espírito realista o que thes sobre de ingenuidade utópica ${ }^{(32)}$.

\section{Trágicas idiossincrasias anglo-americanas?}

Um dos aspetos mais substanciais do confronto geopolítico do pósguerra talvez se possa resumir na máxima da guerra revolucionária: uma ideia só se combate com outra ideia ${ }^{(33)}$. O que originava o desafio de definição das ideias e a crítica dos métodos adotados pelas instituições

(30) James Aronson, The press and the Cold War, Indianapolis-Nova Iorque, The Bobbs-Merrill Co., 1970, p. 33.

(31) «Se existe um dever e ao mesmo tempo uma esperança fundada de tornar efetivo o estado de um direito público, ainda que apenas numa aproximação que progride até ao infinito, então a paz perpétua, que se segue aos até agora falsamente chamados tratados de paz (na realidade, armistícios), não é uma ideia vazia, mas uma tarefa que, pouco a pouco resolvida, se aproxima constantemente do seu fim (porque é de esperar que os tempos em que se produzem iguais progressos se tornem cada vez mais curtos)» Immanuel Kant, ob. cit., p. 171.

(32) Em revista $O$ Direito, ano $83^{\circ}, 1951$, p. 1.

(33) «Trata-se de um conflito de ideias e estas não se combatem com meios materiais de destruição, mas sim com outras ideias, mais nobres, mais generosas. Aqueles meios servirão apenas como suporte, o suporte da garantia da vida de cada um perante o terror que o inimigo desencadeia. Pretender dominar os acontecimentos pela acção isolada do soldado, empregando processos e meios exclusivamente militares, é erro grave das mais graves consequências. $\mathrm{O}$ verdadeiro problema consiste em fazer passar uma população dum estado de espírito para outro estado de espírito. 
envolvidas na guerra psicológica. Essa crítica, tragicamente condenada à marginalidade, evidenciaria um problema ou, se se preferir, um paradoxo insolúvel apontado por Lasswell: «We are in a war of ideas, but we have not found our ideas» ${ }^{(34)}$. Por muito que se insistisse na economia (it's the economy..., como diria décadas mais tarde o assessor de Bill Clinton), o dólar não era uma ideia. Mas era uma imagem e, no final, foi também (ou sobretudo?) na guerra de imagens, encabeçada pela apelativa cultura do entertainment e do welfare, que se decidiu o confronto geoestratégico ${ }^{(35)}$.

A par deste paradoxo, verificou-se um importante erro de cálculo anglosaxónico. Ao contrário do previsto por Churchill com a sua cortina de ferro, bem como da definição operada pela Doutrina Truman, de onde resultou o Plano Marshall, o alvo prioritário do temido «ataque comunista» não foi a Europa mas sim a Ásia. O que transformava o «plano de libertação» num potencial plano de opressão e controlo. A seguir às independências da Índia e do Paquistão em 1947, seguiram-se a vitória maoista em 1949 e a divisão da Coreia em 1950-53. Não foi com planos económicos ou princípios jurídicos que os EUA responderam a esse ataque. Pouco mais de uma década depois do início do confronto bipolar, os EUA mergulharam na mais traumática guerra da sua história em todo o século XX. No contexto português, o «ataque» também se verificaria na Ásia, sobretudo a partir de 1954, com a anexação de Dadrá e Nagar-Aveli pela União Indiana ${ }^{(36)}$.

Dois verdadeiros muros, quais obstáculos de grande valor, se erguem entre a rebelião e o Poder legal: um, psicológico - feito de desconfianças, preconceitos e recusas - e, o outro, ideológico - edificado por uma propaganda ativa e racional que explora temas sedutores, conquanto muitos sem fundamento e até ilegítimos -.

Demoli-los, para que de novo reine a paz no território e sobre ela se possam erguer as bases duma nova vida, dum novo mundo, tal é a finalidade da pacificação.

Todo o trabalho terá de ser orientado no sentido de tocar os corações antes de tocar os espíritos, pois será ineficaz toda a ação baseada apenas em construções do espírito e demonstrações lógicas. Há que começar por 'preparar o terreno' para, só depois, persuadir e converter». Hermes de Araújo Oliveira (coronel), Guerra Revolucionária, $3^{\mathrm{a}}$ ed., Lisboa, 1962, p. 254.

(34) Harold Lasswell, Policy and the Intelligence Function, in W. E Daugherty and M. Janowitz (org.), A Psychological Warfare Casebook, Baltimore, The Johns Hopkins Press, 1958, p. 67.

(35) T. Mattelart, Le Cheval de Troie audiovisuel. Le Rideau de fer à l'épreuve des rádios et télévisions transfrontriéres, Grenoble, Presses Universitaires de Grenoble, 1995, p. 26-27.

(36) No primeiro CM de MC na Presidência, em 19 de julho de 1955, registava o «movimento da independência no N. de África» e o "caso de Goa»: «intensificação da campanha de imprensa da União Indiana contra Portugal», «repetição de atos de sabotagem», «ação de organizações terroristas no nosso território», «organização e conspiração de elementos pró-integração em Goa», "providências diárias de pressão sobre 
Em maio de 1946, por certo impulsionado pelo discurso de Churchill, MC encontrara outro adjetivo para «conjuntura originada pela $2^{\mathrm{a}}$ grande guerra mundial...»: «trágica» ${ }^{(37)}$. Poucos meses depois, um velho deputado manifestava a perspetiva ainda preponderante em S. Bento:

A guerra deixou-nos um magno problema: o de sabermos ou não administrar uma riqueza que nos deixaram. Não podemos contar mais com aplicação de capitais estrangeiros nem com empréstimos externos, ou sabemos administrar o que é nosso, seja qual for o domínio público ou privado onde essa administração tenha de ser exercida ou outros se substituirão a nós na administração do que nos pertence, para se substituírem por fim na nossa própria soberania política. [...] Oxalá o problema político, isto é, o poder de novas origens do poder [sic] não venha retardar mais uma vez o progresso da nossa Pátria. Em 20 anos criámos um Estado e uma política externa independente. Demos às classes dirigentes uma consciência política que há muito a tinham perdido ${ }^{(38)}$.

Por muito «hábil, avisado e prudente» que o regime pudesse eventualmente ter sido, não evitou colocar-se numa posição relativa impossível, provocada desde logo pela simplista análise «dos princípios»:

aquilo que a Europa deixa ver claramente no meio do tumultuar confuso das infelizes populações mortificadas pela fome e pela guerra, é um duelo entre duas ideologias, uma, a oriental, materialista e tirânica, e outra, a ocidental, expressão do espírito a cuja luz a Europa criou a sua civilização e firmou a sua hegemonia no mundo e que não é outro senão o espírito cristão(39).

O combate à ideia ou ideologia oriental não oferece dificuldade:

Tem Vossa Excelência razão quando interroga o futuro sobre os dias que esperam a nossa cultura ameaçada [sic]. Tudo se afigura tão obscuro que quaisquer vaticínios seriam precários. Em frente do imprevisto,

os portugueses na U. Indiana”, "afirmações reiteradas de Nehru de esperança na integração pacífica», «defesa de Damão e Diu e ligação aérea com Goa», «Estatuto da Índia», «melhoria do estado da opinião pública interna e internacional». AMC, cx. 11, MPRE, Notas sobre os Conselhos de Ministros: $\mathrm{n}^{\mathrm{o}} 1$ (19/07/55).

(37) Marcelo Caetano, Hoje, como ontem..., cit., p. 36.

(38) AMC, cx. 34, Correspondência/Lopes, Artur Ribeiro (deputado): $\mathrm{n}^{\circ} 1$ (07/10/46).

(39) Marcelo Caetano, Hoje, como ontem..., cit., p. 41. 
só vejo uma atitude contra o transbordante perigo de uma avalanche comunista e essa consiste em nos unirmos todos, sobretudo os povos da mesma origem e da mesma formação cristã, num movimento de revalorização e defesa dos nossos índices morais e culturais ${ }^{(40)}$.

Já a ânsia de «integrar» o Estado Novo «nos mais genuínos anseios da Europa» democrata-cristã e a colagem estratégica aos EUA (sendo inclusive um dos países fundadores da NATO, em 1948), ignorando as (i)limitações ideológicas americanas, colocava inevitavelmente Portugal e o seu Império na mira da globalizante guerra económica e de imagem a que este procurava escapar:

Foi com surpresa, meus senhores - não o nego! - que por ocasião da última campanha eleitoral [1945] verifiquei ser tom dominante da oposição a apologia da liberdade económica, atacando com arreganho as restrições impostas ao lucro, a disciplina das atividades capitalistas e até - o mais espantoso me parece! - o imposto sobre lucros de guerra! Julgava eu, que o Estado Novo seria sobretudo acusado de não ter feito uma organização económica suficientemente rigorosa para evitar tanto negócio imoral e tanto lucro excessivo que mesmo assim se tem verificado; que seria acusado de não ter tributado mais duramente os grandes rendimentos de modo a poder alargar a sua obra de justiça social. Mas, afinal, o que se reclamou foi a supressão de toda a organização, o que significaria o regresso à liberdade de ganhar de qualquer maneira - à liberdade de explorar o povo! Será que ao espírito fechado de muitos não se revelou ainda que o tempo da liberdade económica passou por uma vez? ${ }^{(41)}$.

A convicção com que MC se manifestava «pouco disposto a transigir com os abusos do capitalismo e as injustiças criadas pelo egoísmo dos homens», tal como a declaração de que «a propriedade deve ser uma garantia da liberdade e não um instrumento de opressão», não era acompanhada pelo sucesso da ideia, apesar do apoio geral ao seu discurso $^{(42)}$. Não por acaso, nas 53 páginas desse discurso de 1946, MC

(40) AMC, cx. 27, Correspondência/Fontoura, João Neves da (diplomata e político brasileiro): $\mathrm{n}^{\mathrm{o}} 1(22 / 07 / 44)$.

(41) Marcelo Caetano, Hoje, como ontem..., cit., p. 46-47.

(42) AMC, cx. 33, Correspondência/Lima, A. Carlos (advogado): n 1 (28/05/46); AMC, cx. 33, Correspondência/ António Augusto Pires de Lima (diretor-geral do Ensino Secundário, empresário no Porto): $n^{\circ} 1(03 / 06 / 46)$. 
não refere uma única vez a palavra corporativismo. Apenas menciona timidamente, uma vez, os organismos corporativos. A ideia falhava. $\mathrm{O}$ anticomunismo exacerbado estava em perfeita sintonia com os EUA. Mas o restritivo intervencionismo económico era um obstáculo para os objetivos planetários da superpotência.

De igual modo, verificava-se a concentração da irracional repressão anticomunista na Europa. Facto não compreendido por elementos do próprio regime. Em fevereiro de 1961, um elemento da Comissão de Moçambique da UN referia que «Há quem discuta, mas não há partidos internos pró-independência como há ali [Angola]. A massa pode ouvir os que arengam nos cafés ou envenenam os jornais (só agora, depois de muito insistir, se mandou a gente da censura!)» ${ }^{(43)}$. MC criticava a atuação da PIDE: «deficiências da nossa polícia. Como a polícia é tanto mais violenta quanto mais incompetente. A prisão discricionária é o «céu dos juristas». Há realmente um problema». Posição baseada nas ideias de que a «força moral nasce do assentimento» e de que «resiste-se a uma pressão temporária de um regime estrangeiro» mas «não se resiste ao espírito do tempo» ${ }^{(44)}$. De notar que MC foi o último ministro das Colónias dum mundo (ainda) eurocêntrico. O processo descolonizador começou seis meses depois de ser demitido.

\section{Propaganda: um elemento perturbador?}

Antes de Nehru ser posto em liberdade (1945) e antes da pioneira independência do Paquistão e da Índia (agosto de 1947), o cardeal Cerejeira visitou África como legado apostólico para a sagração da catedral da cidade de Lourenço Marques. A visita terminou em Angola precisamente quando MC assumia a pasta das Colónias. No discurso de despedida declarou, dez anos depois de MC o ter feito num jornal metropolitano, o seguinte: «Trago os olhos cheios desta África gentil [...]. Levo para Portugal a aurora deste mundo novo, deste Brasil do Século XXI» ${ }^{(45)}$. Era a versão mais explícita dessa expressão singular da política colonial portuguesa.

(43) AMC, cx. 38, Correspondência/Mesquitela, Gonçalo Castelo Branco da Costa de Sousa de Macedo (advogado; membro da Comissão de Moçambique da U.N.): n 28 (25/02/61).

(44) José Freire Antunes, Salazar Caetano..., cit, p. 148-149.

(45) Em jornal O Intransigente, de Benguela, no 925, 15 set. 1944. Citado em AMC, cx. 25, Correspondência/Durães, António (advogado, presidente da Câmara Municipal de Benguela quando MC era ministro das Colónias): nº 1 - anexo 1 (11/69). 
Embora este episódio propagandístico deva ser enquadrado no âmbito da estratégia da Santa Sé para África, não é de admitir que Cerejeira, apesar das fricções, proferisse qualquer declaração em desacordo com o regime:

Chegada do Patriarca. Envio junto a nota recebida da Agência-Geral das Colónias, a quem encarreguei da recepção (i.e., de organizar o programa). Acho bem. Peço que me diga logo que possa se acha bem também. Claro que entendo dever o Ministro das Colónias ir a bordo, mesmo sem o cardeal ser legado. E que por cortesia devem o Chefe de Estado e membros do Governo enviar também pessoal dos seus gabinetes apresentar cumprimentos à chegada $a^{(46)}$.

O desenvolvimento da guerra psicológica e da arma da propaganda, tão indispensável no plano de dominação planetária nazi como na resposta aliada, ocorreu precisamente durante a II Guerra Mundial. O pós-guerra consagrá-las-ia na emergência do novo paradigma militar: a guerra entre (os) povos e entre (os) civis $^{(47)}$. Semelhante aspiração não desapareceu com a morte de Hitler e a destruição do NSDAP ${ }^{(48)}$. Os dois sistemas com pretensões igualmente planetárias consagraram um discurso bipolar. Por um lado, a psychological war, a guerra de ideias ou luta ideológica atribuída, segundo an western point of view, exclusivamente ao aparelho soviético. Por outro, o discurso místico universalista e globalizante do american way (and will) of life, acrescido da subdivisão geoeconómica, segundo o eixo do desenvolvimento nortesul a que já se fez referência, numa tentativa de disputa pela influência nos países (presentes e futuros) do chamado Terceiro Mundo.

Nesse sentido, westernization passara a significar modernização e desenvolvimento ${ }^{(49)}$. A doutrina do free flow of information foi o necessário

(46) José Freire Antunes, Salazar Caetano..., cit., p. 124.

(47) Ver Rupert Smith, A utilidade da força..., cit.

(48) Repare-se no paralelismo existente com a reformulação operada pelo «pai» do conceito de "planetarização», Pierre Chardin, na obra O Fenómeno Humano, entre 1938-40, quando foi originalmente escrita, e 1947-48. Pierre Teilhard de Chardin, Le Phénomène humain, Paris, Seuil, 1955; O fenómeno humano, Paulus, 1998. Armand Mattelart, História da Utopia Planetária: da cidade profética à sociedade global, Lisboa, Bizâncio, 2000, p. 288-290.

(49) Ver Walt W. Rostow, The dynamics of Soviet Society, New York, New American Library, 1954; The Stages of Economic Growth, Cambridge, Cambridge University Press, 1960; A proposal: key to an effective foreign policy, Max F. Millikan (co-autor), New York, Harper \& Brothers, 1957. 
suporte da estratégia de eliminação de todos os obstáculos a um livre comércio mundial. Ou seja, a internacionalização ou «exportação da $1^{a}$ emenda» à Constituição Americana ${ }^{(50)}$, segundo a ideia de que todos deveriam passar a viver «na» América ${ }^{(51)}$, apresentada «como consciência do mundo» ${ }^{(52)}$. Conforme Kissinger sugere, mesmo quando os EUA fazem mal, fazem-no por bem, permanentemente condenados a redimensionar o discurso wilsoniano. $\mathrm{Ou}$, numa reatualização da proposição rousseauniana, os EUA são naturalmente bons, o mundo é que os corrompe. Um discurso adaptado à ideia de descolonização, mas, em última estância, ao serviço do dólar.

\section{Sentidos do último esforço (des)colonolizador europeu}

Enquanto MC foi ministro das Colónias, o governo de Sua Majestade não evidenciou qualquer sinal de mudança estratégica. Pelo contrário, deu sinais no sentido de reforçar a presença em África. Em dezembro de 1946, The Crown Colonist noticiava orgulhosamente: «New headquarters for the Colonial Empire» - «Decision to erect a 'fitting' building in Westminster: Temporary home for Colonial Office in Church House», "worthily expressing the high value which the people and Government of this country place on the friendship of the Colonial peoples» ${ }^{(53)}$.

A determinação belga não era diferente. $\mathrm{O}$ modelo sim, apresentava algumas nuances. MC parece ter apreciado mais a autoridade colonial belga, até pela influência do Congo em Angola. Pela mesma altura, a imprensa belga, através do general Georges Moulaert, identificava o caminho para combater os «problèmes coloniaux immédiats», suportado pela transferência para o Congo de «1 milliard 200 millions»:

Cette somme sera consacrée à un fonds social indigène et subsidiera la Recherche Scientifique. [...] Quels sont les problèmes primordiaux

(50) Ver M. A. Blanchard, Exporting the First Amendment: the Press-government cruzade of 1945-1952, White Pains, N. I., Lonhman, 1986.

(51) Ver W. E. Daugherty and M. Janowitz (org.), A Psychological Warfare..., cit.

(52) Henry Kissinger, A Ordem Mundial: reflexões sobre o carácter das nações e o curso da história, Lisboa, Dom Quixote, 2014, p. 297-339.

(53) AMC, cx. 8, Diamang - Gabinete do Ministro, correspondência com o Administrador-Delegado em Lisboa: $n^{\circ} 8$ - anexo 6 e 7 (12/46). 
indigènes? Est-ce l'instruction publique, la «mass éducation», l'amélioration du logement, les écoles professionnelles et même moyennes? Non! Nous devons avant tout assurer la vie de nos populations. Premier Probléme: l'assistance médicale indigène.

Quando as economias coloniais estavam demasiado dependentes do setor primário, em especial da extração mineira, MC parecia focado no futuro. Essa preocupação explica que tenha destacado o seguinte parágrafo:

En fait, on exportait pour un prix infime et désoire [sic] la fertilité du pays. [...] M. Harroy écrit que l'exploitation minière appauvrit le pays. Cela est inexact. Les Mines permettant d'outiller le pays, de construire des routes, des chemins de fer, d'organiser les services administratifs, médicaux et sociaux, de développer l'agriculture vivrière, mais tout cela à condition de permettre un jour le remplacement des richesses du soussol par le développement indéfini des richesses de culture; c'est-à-dire à condition de maintenir et d'améliorer la fertilité des terrains ${ }^{(54)}$.

Em França, começava a desesperar-se na «recherche d'un nouveau Colbert». Jean Walter, num artigo publicado na revista Paysage (de 25 de novembro de 1945), alertava a França (e a Europa) para o perigo decorrente da guerra ideológica. Enquanto as superpotências sufocavam o mundo com propaganda, absorvendo-o no debate político, a sua hegemonia económica consolidava-se a traços largos: «Tant à l'intérieur qu'à l'extérieur de notre pays, les évènements politiques ont pris, au cours des dernières semaines, une telle ampleur que l'essentiel du problème mondial et du problème national de reconstruction est passé au second plan dans nos préoccupations immédiates». Nesse sentido, propunha-se o regresso da reconstrução económica ao discurso político.

O princípio do "primauté de l'économique», resumindo todos os problemas da França no facto de esta se encontrar «à la recherche d'un nouvel équilibre économique». Focou a questão dos equipamentos materiais e dos serviços, mas o que chamou mais a atenção de $\mathrm{MC}$ foi «le problème des cadres». Destacou a importância de criar quadros

(54) AMC, cx. 8, Diamang - Gabinete do Ministro, correspondência com o Administrador-Delegado em Lisboa: $\mathrm{n}^{\circ} 8$ - anexo 8 (12/46). 
administrativos qualificados e eficazes, bem como a crítica dos vícios da função pública:

L'intrusion du politique dans l'économique a fait que le contrat exprès ou tacite qui lie le fonctionnaire à l'Etat peut s'exprimer ainsi: en regard de faibles traitements, d'une situation sociale de seconde zone, le préposé de l'Etat acquiert deux privilèges: la stabilité, l'irresponsabilité. [...] Il faut reconnaitre et proclamer que sans une administration compétente, énergique, bien payée et sans cesse soumisse á la loi du rendement, toute réforme restera théorique et sans prise effective sur des réalités auxquelles nul ne saurait échapper(55).

\section{Singularidades do modelo económico imperial britânico}

Dado que o discurso «integrista-civilizador» tendia a ser inversamente proporcional à capacidade económica, os interesses anglo-saxónicos focavam-se sobretudo na prevenção teórico-sistémica contra o aumento do nível de vida indígena. MC seguiu com avidez os debates e as tendências político-económicas inglesas e belgas. Chegava a pedir indicações bibliográficas a Vilhena, diretor da Diamang ${ }^{(56)}$. $\mathrm{O}$ artigo publicado no $\mathrm{n}^{\mathrm{o}} 5351$ do britânico The Economist, de 16 de março de 1946, mereceu a maior atenção. Baseado nos relatórios do Labor Advisor to the Colonial Office britânico, major Orde Browne, sobre as condições do trabalho na África Oriental, o artigo destacou a «enorme diferença» entre o trabalho em África e na Europa, resumida na seguinte ideia sublinhada por MC:

The African is still largely independent of paid work for his subsistence, although he may, to an increasing extent, find paid work for a few months at a time in order to earn enough money to raise his subsistence level. But

(55) AMC, cx. 8, Diamang - Gabinete do Ministro, Artigos e Comunicações sobre questões africanas: $\mathrm{n}^{\circ} 1(25 / 11 / 45)$.

(56) «Conhece algum livro moderno sobre a organização económica e política do congo Belga? [...] Interessava-me, sobretudo, conhecer a estrutura económica e financeira de toda essa teia de sociedades do Congo Belga, lançadas pela Société Générale de Belgique». AMC, cx. 8, Diamang - Lisboa, Documentação recebida do Administrador-delegado em Lisboa: $n^{\circ} 6(26 / 04 / 46)$. Dias depois ( $n^{\circ} 7(06 / 05 / 46)$, MC recebia «algumas publicações interessantes sobre assuntos coloniais saídas de alguns anos a esta parte», maioritariamente belgas e inglesas, sobre problemas de economia, administração, nutrição, medicina, educação. Denotava grande preocupação com todos os parâmetros de desenvolvimento humano, social e económico. 
he is a «target worker». He intends to earn a certain sum and then go back home again, and the sooner this sum can be obtained the better. Thus the offer of a higher wage has few attractions; it enables him to go home earlier, but it does not persuade him to stay longer or work harder. Hence the frequent statement that higher wages mean less work ${ }^{(57)}$.

Ou seja, salários mais altos significariam menos trabalho. A última frase foi destacada até à exaustão pela Diamang - «More Wages, Less Work»-, que, por motivos óbvios, inundava o Ministério com artigos do The Crown Colonist:

Though the Northern Rhodesia Government has long since learnt of the Africans' disinclination to work, nothing has been done to improve the situation. Sir Stewart Gore-Browne's admirable report on labor conditions in the territory in 1938 fell on deaf ears. His statement that increased wages were no solution to the problem has been amply proved. While wages have doubled in three or four years, efficiency has steadily decreased. Something effective must be done without delay if conditions are not to become intolerable. It is almost inevitable that the Africans have a period of austerity before them ${ }^{(58)}$.

Sabe-se como o poder colonial norte-europeu só era democrático na Europa, já que em África, pelo contrário, era centralista e autoritário. O mesmo se verificava quanto ao modelo económico-social. Os trabalhistas britânicos no poder ${ }^{(59)}$ eram keynesianos na Europa e ultraliberais em África, não dispensando nem a ameaça da «austeridade», segundo o artigo supracitado, nem uma visão catastrofista em relação à possível introdução do modelo social-europeu em África ${ }^{(60)}$.Tanto ou mais do que o fator «tempo», em conjugação com a evolução político-ideológica no pós-guerra, estes caracteres culturais europeus foram transversalmente determinantes para os processos descolonizadores em África.

(57) AMC, cx. 8, Diamang - Gabinete do Ministro, Artigos e Comunicações sobre questões africanas: $\mathrm{n}^{\circ} 2(16 / 03 / 46)$.

(58) AMC, cx. 8, Diamang - Gabinete do Ministro, correspondência com o Administrador-Delegado em Lisboa: $\mathrm{n}^{\circ} 8$ - anexo 2 (12/46).

(59) Governo de Clement Richard Attlee (1883-1967), que vencera as eleições britânicas de Maio de 1945 contra W. Churchill. Governou até outubro de 1951.

(60) AMC, cx. 8, Diamang - Gabinete do Ministro, Artigos e Comunicações sobre questões africanas: $n^{\circ} 2(16 / 03 / 46)$. 


\section{Cultura e caráter?}

Durante a longa viagem ministerial a África (1945), MC produziu duas reflexões íntimas absolutamente nucleares. A primeira parece ter sido anotada no regresso a Lourenço Marques, após a visita à África do Sul. Escreveu então:

O português na colonização. Problema de enquadramento técnico. Problema da honestidade comercial e do sacrifício do lucro imediato ao sucesso firme e final. Espírito de enriquecimento rápido. Urbanismo: os filhos dos agricultores são doutores (o doutorismo clássico da nossa terra). (Onde a questão da Universidade e da escola portuguesa e o problema dos educadores). O progresso, a cultura e a imaginação. Temos a imaginação devaneadora - falta-nos a imaginação criadora, que é a fecunda.

De como colocamos sempre o centro do progresso colectivo e do nosso próprio sucesso individual nos outros. Daí, em vez do exame de consciência e do espírito de reforma e aperfeiçoamento de nós mesmos, sempre a ideia de uma reforma social e política. Ora enquanto os homens não forem melhores há-de sempre ser necessário fazer mais leis e ter mais barreiras ${ }^{(61)}$.

No relatório final não deixou de reproduzir esse pensamento, como as demais impressões colhidas: "raro é o europeu que procura os trópicos com outra ideia que não seja enriquecer. $\mathrm{O}$ dinheiro e tudo o que a ele conduz e se refere, assume assim um prestígio e uma sedução demoníacas. [...] A mentalidade puramente gananciosa de muitos dos que depois deles ficaram» desafiava a construção duma «humana e justa legislação sobre trabalho dos indígenas» ${ }^{(62)}$. Uma ideia reforçada pelo impacto duradouro da figura de Smuts ${ }^{(63)}$ - «primeira impressão de Smuts, boa. Vivo, fresco, espirituoso e bondoso» - e sua visão do mundo:

Confessou-se individualista e seriamente preocupado perante os problemas do futuro. A Europa, cabeça e centro do mundo está diminuída, empobrecida e arruinada - vai ter nos próximos anos gravíssimos problemas a defrontar; mas a América ainda os terá piores. Estive há dias na Itália onde

(61) AMC, cx. 10, VMA, Notas apontamentos e outros escritos: $\mathrm{n}^{\circ} 1$, fl. 23v $(06 / 45-11 / 45)$.

(62) AMC, cx. 10, VMA, Objetivos da Viagem: n 1 - fl. 10-13 (s.d. - nov./dez. 1945).

(63) Recorde-se a citação de Smuts em Marcelo Caetano, A Opinião Pública no Estado Moderno, Lisboa, 1965, p. 60. 
disse aos membros do governo ${ }^{(64)}$ : os senhores aqui estão numa situação difícil, porque se encontram perante os graves problemas da pobreza, mas eu venho dos Estados Unidos onde vi desenharem-se outros problemas ainda mais graves, os problemas da riqueza. A avidez de bem-estar de toda a gente cria um nível de vida geral impossivel de sustentar, seja por que país for. Essa é a mais melindrosa questão do porvir. Espraiou-se em considerações sobre a mais grave crise da história do mundo que vai necessariamente surgir dentro dos próximos 50 anos - porventura dentro de 20 ou 30 , e que será uma catástrofe terrível ${ }^{(65)}$.

\section{O segundo texto foi escrito no final da viagem, em Luanda.}

Aqui [Angola] como em Moçambique o Ministro é recebido como Messias - a visita como descida redentora ${ }^{(66)}$. Chovem exposições, reclamações e memoriais sobre pretensas injustiças e aspirações insatisfatórias: foram numa e noutra costa às centenas e a maior parte versando coisas sucedidas há anos. Toda a gente tem qualquer coisa a pedir ao Estado e a esperar do Estado. O colono (latu sensu) considera um sacrifício pela pátria a sua presença em África que só por si merece apoio, gratidão e amparo. Os piores males que porém me parece eivarem a colonização (como a vida social inteira ${ }^{(67)}$ ) portuguesa, são a falta de cultura e a falta de carácter. Chamo falta de carácter à inexistência nos homens, em geral, de um sistema de princípios morais e de crenças que os orientem e regulem na sua conduta individual. Os portugueses hoje não têm este carácter. E não têm cultura. Até mesmo (e talvez sobretudo) os das elites são espantosamente incultos - das coisas técnicas e das coisas gerais, sem o sólido assento duma preparação fundada em qualquer dessas disciplinas de espírito, as línguas mortas ou as matemáticas, e sem iniciativa, engenho, visão. Que destino nos reserva o futuro no mundo

(64) O primeiro governo da «nova Itália», liderado por Ferruccio Parri, do Partido de Acção, formado após um amplo acordo com comunistas, socialistas, liberais, democratas cristãos e trabalhistas.

(65) AMC, cx. 10, VMA, Notas apontamentos e outros escritos: $\mathrm{n}^{\circ} 1$, fl. $27(06 / 45-11 / 45)$.

(66) Um quarto de século depois, nada tinha mudado: «Senhor Professor, pois digase o que se disser, é patente que Portugal há muito não tem chefes à altura. [...] Seja V. ${ }^{a}$ Ex. ${ }^{a}$ o Messias que ele há tanto tempo espera. E V. ${ }^{a}$ Ex. ${ }^{a}$ pode sê-lo, se quiser». AMC, cx. 41, Correspondência/Oliveira, João Duarte de (deputado): n ${ }^{\circ} 1$ (17/02/71).

(67) Comentário, em Lourenço Marques, sobre a revista à portuguesa: «Claro: a revista como em Portugal - muitas piadas com duplo sentido grosseiro, muita crítica derrotista, muito sentimentalismo piegas com faduncho à mistura. Mas nós somos assim mesmo e aqui é Portugal...» AMC, cx. 10, VMA, Notas apontamentos e outros escritos: $n^{\circ} 1$, fl. 30v (06/45-11/45). 
[...] se não estamos apetrechados para a concorrência no domínio da economia, da técnica ou da política? ${ }^{(68)}$.

Subjaz aqui a ideia de que uma mudança coletiva só será efetiva quando precedida por uma transformação individual, num processo endógeno e não por constrangimento exógeno. Daí a necessidade do designado «sistema de princípios». Embora MC, neste caso, não se assumisse otimista. Em maio de 1944, numa conferência na Associação Comercial de Lisboa, afirmava que se havia «constante da História em que [ele] acredite a olhos cegos é a natureza humana. A guerra não transformará nem melhorará a natureza humana» ${ }^{(69)}$. A complementaridade necessária entre o legalismo, que tem por objetivo impor o padrão, e a virtude, que convida a assumir esse mesmo padrão, poderia eventualmente remeter, ainda segundo a mesma linha de pensamento, para duas possíveis limitações do discurso políticoideológico: a ausência de credibilidade provocada pela secundarização do «sistema de princípios» e a impotência de qualquer «sistema político» perante os caracteres individuais ${ }^{(70)}$.

(68) AMC, cx. 10, VMA, Notas apontamentos e outros escritos: $\mathrm{n}^{\circ}$ 1, fl. $72(06 / 45-11 / 45)$.

(69) Marcelo Caetano, Predições sem profecia sobre reformas sociais, Lisboa, 1945, p. 8.

(70) No prefácio a uma obra de 1963, MC escreveu: «É esse mesmo calor humano que põe na evocação de figuras como Maximiano Lemos ou Abel Salazar. Nas páginas que lhes dedica não se limita a traçar biografias ou a narrar episódios: palpita nelas uma emoção feita de veneração e de estima que atrai o leitor à melhor compreensão dos mestres evocados. E é de compreensão que estamos carecidos neste País onde os homens se acham tão divididos e onde é tradição (infeliz e malfadada tradição!) esquecer ou denegrir quantos conseguem levantar a cabeça alguma polegada acima do mar da mediocridade.

O dom de admirar constitui um traço de generosidade do espírito, sinal de estar isento da mesquinhez de carácter que nega sistematicamente aos outros aquilo que se não encontra em nós. Que só se admire o que é admirável, decerto. Admirar qualidades medíocres é a condenação ao destino charro da mediania moral. Mas que não sirvam de obstáculo a essa forma de comunhão humana a divergência ideológica ou os contrastes temperamentais. Para além do que separa os homens há largos campos abertos ao entendimento dos espíritos e até ao encontro das sensibilidades e dos afetos. A atitude do autor perante Abel Salazar o prova uma vez mais». Fernando de Castro Pires de Lima,

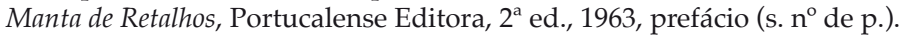

